\title{
Nômades e peregrinos: o passado como elemento identitário entre os ciganos calons na cidade de Sousa-PB
}

\author{
Maria Patrícia Lopes Goldfarb
}

\begin{abstract}
resumo Este trabalho analisa elementos da identidade cigana presentes em suas formas de identificação coletiva, como esta identidade é narrada e os elementos que articulam uma visão de grupo social. Para isso, toma como modelo empírico grupos ciganos residentes na cidade de Sousa (PB). Aborda ainda a importância da religiosidade para uma parcela significativa da comunidade cigana no tocante a sua identidade cultural.
\end{abstract}

palavras-chave Ciganos. Identidade. Memória. Religiosidade. Narrativas.

\section{Introdução}

$\mathrm{Na}$ cidade de Sousa encontra-se a maior população cigana do estado da Paraíba, regiáo Nordeste do Brasil. São três grupos que estâo localizados próximos à $\mathrm{BR} 230$, a $3 \mathrm{~km}$ do centro, no âmbito periférico da cidade ${ }^{1}$. Os grupos residem próximos ao parque de exposiçôes de animais e à Escola Técnica Federal da cidade. Tais grupos estáo sedentarizados desde a década de 1980, e sua fixação baseou-se na articulação de alianças entre líderes e políticos locais, desenvolvendo assim formas de fixação e estratégias de trocas. A sedentarização e a criação de uma "comunidade cigana" basearam-se na articulação de alianças entre os líderes e um poder paternalista, com atitudes assistenciais.

As áreas onde se localizam os grupos foram parcialmente doadas por tais políticos, embora quase ninguém possua documentação correlata. Os grupos são formados por núcleos familiares, ligados entre si por relaçôes de parentesco. Cada um possui um líder que, na prática, representa uma espécie de intermediador com o mundo externo.

Estes grupos podem ser definidos como uma parcela pobre da cidade, morando em péssimas condiçôes sanitárias, expostos a diferentes formas de descaso e de discriminaçóes. Os ciganos compreendem grupos específicos e distintos do ponto de vista cultural, grupos que se pensam e são pensados como diferentes, embora no imaginário nacional sejam representados através da ausência de raízes e de uma liberdade exacerbada, frutos de representaçôes que os ligam ao nomadismo.

Para analisar o estabelecimento da identidade cigana, tomo como base o pensamento do antropólogo Fredrik Barth (1998), buscando situar as formas de diferenciação social existentes em Sousa, visto que, conforme Barth, não é o isolamento geográfico ou social que representa o fator definidor da diversidade cultural. A identidade, que pode ser desenvolvida no plano das açôes ou das narrativas, representa um recurso indispensável para a criação de um nós coletivo, fundamental ao sistema de representaçóes através do qual os grupos podem reivindicar um espaço de visibilidade e de atuação sociopolítica.

Verificou-se que entre os ciganos de Sousa a articulação da memória surge como um 
recurso indispensável à identificação de suas especificidades culturais, o que corresponde às experiências vividas ou tematizadas pelos grupos, essenciais para a análise das formas de identificação coletiva. Assim, há um exercício de memória que se relaciona com a necessidade de distinção frente à sociedade envolvente, onde as concepçóes de tempo (passado/presente) e espaço (viagens/moradia) são fundantes, num exercício de autodefinição de sua identidade coletiva.

Os dados da pesquisa foram adquiridos graças a um conjunto de procedimentos metodológicos denominado etnografia. O método etnográfico é comumente conhecido pela necessidade de uma aproximaçáo mais intensa entre pesquisador e pesquisados, com observação direta e participativa, que permite uma posterior reflexáo teórica sobre os dados coletados. Durante o trabalho de campo o pesquisador pode utilizar diferentes fontes ou recursos, o que lhe dará acesso aos "pontos de vista" ou comportamentos analisados (Giumbelli, 2002).

Também realizei entrevistas abertas (Thiollent, 1982) com cerca de 50 pessoas, membros da comunidade cigana, buscando captar suas formas de identificação cultural. Compreendo a entrevista como um diálogo que se desenvolve no campo da intersubjetividade, o que implica uma troca de valores, representaçóes e emoçóes ${ }^{3}$.

A pesquisa de campo junto à população cigana desenvolveu-se em diferentes períodos. Um primeiro levantamento de dados teve início em 1998, período em que residi durante seis meses na comunidade. Outras incursões ao campo de pesquisa foram feitas nos anos de 2003, 2004 e 2009 (cada uma com duração de cerca de dois meses), quando, entre outras coisas, busquei levantar junto aos grupos ciganos os discursos sobre o nomadismo e as diversas formas de narrá-lo, bem como reavaliar os dados de pesquisa ${ }^{4}$.
Foram adotados como critério de seleção para as entrevistas pessoas de ambos os sexos que viveram a época do nomadismo, diferenciando-os da população mais jovem, que não chegou a viajar com os grupos. As entrevistas foram bastante significativas na apreensão do imaginário sobre o passado dos grupos ciganos, bem como para o resgate das representaçóes instituídas pela coletividade e pelo trabalho da memória coletiva.

É preciso destacar que, embora não seja o único elemento usado pelos ciganos na definição de sua identidade cultural, a memória mostrou-se fundamental durante a pesquisa, e verificou-se a importância da história oral no processo de produçáo do passado, ou melhor, de um passado, das concepçóes que a comunidade tem de sua história e das percepçóes de tempo e lugar, motivo pelo qual este artigo aborda este aspecto 5 .

O trabalho de campo possibilitou constatar, ainda, que há uma articulação bastante significativa entre religiosidade e identidade cigana para uma parcela considerável desta população, o que é aqui analisado.

\section{A memória do passado}

A memória representa um conhecimento de si e do mundo desenvolvido através do trabalho de recordar, pois como nos diz Bachelard (1994, p. 51), é "narração", não "recitação". Deste modo, é aqui enfatizada por representar uma importante arma na luta dos ciganos pela diferenciação e identificação coletiva, pois tanto lembrar como esquecer são processos atuais e constantes entre os grupos sociais.

Baseio-me, sobretudo, no conceito de memória coletiva de Maurice Halbwachs (1990), onde a memória é construída de acordo com os grupos sociais de referência, sendo, portanto, um trabalho dos sujeitos em sociedade. A memória diz respeito à construção de quadros de 
significação temporal e espacial, onde as lembranças resistem às transformaçóes e se articulam a novas referências, sem deixar de existir. Entender o que é mantido através do exercício da memória coletiva nos permite compreender que é nesta senda que se descortinam formas de apresentaçáa do tempo. O caminho propóe um resgate dos registros de memória e das formas como esta atua no presente.

Em busca dos elementos constitutivos da identidade cigana, verifiquei que o período nômade vivido pelos grupos, bem como as imagens que circulam em torno deste, é extremamente importante por ser um elemento constante nas definiçôes do "ser cigano". E falar de passado é falar de tempo, um tempo que não existe mais de fato, mas continua a existir na memória dos ciganos.

Para Bosi (1994), a memória se constitui por uma espécie de substrato fluido: o tempo, que é qualificado através de lembranças, pensadas como evocação sistemática do recordar e situar o passado numa escala significativa de acontecimentos (vividos ou imaginados). A concepção de temporalidade é vista pelos informantes como algo singular, como projeção das experiências vividas no passado e no presente. Assim, a organização do tempo nos mostra o quanto a memória é importante para estes grupos, sendo o que permite um retorno ao "tempo de atrás", tido como uma espécie de tempo mítico.

Neste sentido, pude evidenciar que, ao falar do passado, há entre os ciganos uma preocupação em demarcar a origem e construir a história do grupo através do significado simbólico das "viagens", onde os traços significativos deste passado servem para representar sua identidade cultural num espaço de morada fixa e, por fim, o posicionamento de cada sujeito frente à sociedade envolvente e ao seu grupo de pertencimento.

Se é cigano porque é uma pessoa ativa, é coisa dada, deixada por Jesus mesmo, é o sinal de cigano, já veio dos tempos de atrás, vem de uma cidade que nós mesmos não conhecemos, só conhecemos pelo pessoal antigo, que o cigano é filho natural do Egito, todos os ciganos. Mas não sei dizer, náo chegou no meu conhecimento o nascimento, a posição dos ciganos, mas sei que foi sempre viajando pelo mundo (D, 66 anos).

Os ciganos são pessoas sempre muito humilhadas, mas muito protegidas por Deus, pois nós ama muito a Deus, todos os ciganos. Porque os ciganos, nós somos definidos como pessoas assim, de vida errante. A diferença de quem é cigano e quem não é, é porque o outro povo vivia de morada e os ciganos vivia andando, perambulando pelo mundo, era essa diferença, compreende? (L, 78 anos).

Com base nas falas, podemos perceber uma relaçáo com a produçáo de um mito de origem: passado nômade que remonta ao Egito e a passagens bíblicas, e que se apresenta como bastante eficaz na construção de diferenciaçóes com o mundo externo. Conforme Weber (1994, p. 270), trata-se da crença subjetiva de que existe uma afinidade de origem, crença essa que pode ancorar-se apenas no desejo de diferenciar-se, mas que é capaz de desenvolver uma força criadora da comunidade, quando apoiada na lembrança (ou imaginação) de um período de imigrações.

Como podemos verificar, as recordaçóes têm sua gramática específica e foram analisadas através das narrativas sobre o passado, que aparece como algo antigo, naturalmente dado, que remonta a um tempo milenar e divino. Para alguns informantes "Deus" também seria responsável pela resistência cigana, o que significa dizer que, em comparação com o não cigano, os ciganos seriam muito mais fortes e persistentes perante as adversidades sociais e econômicas e as pressóes do tempo.

Analisando as falas constatei a importância da memória para tais grupos, que procuram no 
passado coletivo imagens e significados para a vivência do presente. Para os grupos ciganos, o processo de relembrar representa um meio de explorar os significados da experiência coletiva do nomadismo. E pensando nisso, este período é tido como um acontecimento inaugural, que ganha grandes proporçôes no tempo presente.

Com base em Bachelard (1994) e Eckert (1993), penso que a memória é uma espécie de força capaz de reinventar o cotidiano, de fornecer aos sujeitos sociais um modo de interpretar o passado e significar o presente. A memória, portanto, relaciona-se com a capacidade reflexiva frente aos significados socialmente transmitidos. Assim, o passado nômade é narrado pelos ciganos como uma espécie de essência que não se perde, que se mantém, que representa o alargamento das fronteiras do presente e de um tempo ido.

\section{O passado nas narrativas dos idosos}

Conforme destacado, fatos do passado são narrados como uma espécie de matéria-prima na definição do "ser cigano", retendo-se na memória apenas aquilo que merece ser lembrado. Assim, as pessoas integram em suas falas sentimentos sobre o que foi visto, vivido, sentido, imaginado - fruto do processo coletivo de identificação com uma história que é resgatada ou construída. Neste sentido, o tempo está contido na imagem dialética do recordar, onde o passado é pensado através de um presente comparado.

Muitos informantes ligam o surgimento do grupo à ideia de destino, aos poderes divinos, à vontade de Deus:

Cigano é o seguinte, nós ciganos fomos colocados por natureza, tá entendendo? Por Deus. É como, vamos supor, tem a parte cigana e a juron. Aí nosso nome foi colocado de cigano pelos gringos, aí por isso ficaram chamando "ciganos" (N., 27 anos).
Verificamos na fala acima que ser cigano representa um empreendimento natural, visto que divino. E Deus seria o responsável pelo passado de nomadismo que o diferencia do "juron" ${ }^{6}$.

Denominaçôes como "esta vida" de "andar pelo mundo", de não ter "paradeiro", de viver mudando de lugar denotam uma definição dos ciganos através do nomadismo, bem como o sentimento ou a crença numa origem comum. Entretanto, tais crenças se manifestam sob formas diferentes, de acordo com as experiências de vida e a geração dos indivíduos. É necessário frisar que especialmente a população idosa sublinha a tradição milenar, apelando sempre para as referências bíblicas:

Hoje nós deixamos a vida que Deus nos deu e estamos morando. Porque a nossa vida vem da vida de José, do Egito, Abraão, Isaac, Moisés, de quando eles andavam. E os ciganos foram... E assim viemos para o Egito, saímos da Índia e viemos para o Egito, isso os ciganos mais velhos. Eu não, já sou brasileiro, filho do Brasil. Lá onde os ciganos mais velhos saíram da Índia para o Egito, para a Palestina, e de lá da Palestina teve muitas partes de ciganos que vieram para a Itália e outros para Portugal... Os ciganos sempre são pessoas amantes a Deus, nós ama muito a Deus... Quem dominava os ciganos era Abraão e Sara, os três reis magros que eram ciganos, Isaac, Moisés, todos faziam parte dos ciganos. Os ciganos mais velhos diziam a nós que isso tudo era parte deles. Olhe, quando Abraão veio para Canaã conduziu muitos ciganos e daí foram distinguindo, foram saindo uns prum canto e tiveram outros que, perseguidos pelo rei, saíram para Itália, outros para Portugal. Esses ciganos da Bahia, do Pernambuco são trazidos da Itália, são italianos. Eu sempre digo que a nossa vida era uma vida boa, que nós confiávamos em Deus, e confia! Mas não tá mais como nós queríamos! Nós queria morrer 
na nossa vida, andando, fazendo a parte como Jesus Cristo fez. Porque Deus também foi nômade, ele andou muito pelos países, ele foi cigano também, andou entre os ciganos, ele fez muitas coisas de exemplos para o povo, curou muitas pessoas. Tem muita gente que diz que não tem ciência, mas Deus teve entre os doutores, entre os sábios, ensinou, deu ciência para o homem. O homem inteligente faz coisas porque Deus disse: "aquele que crê em mim fará o que eu faço", na sua palavra (...). Tantos que tem por aí que não pegam numa enxada e vive bem, por quê? Porque confia em Deus. Agora que riqueza não leva ninguém ao céu porque disse Deus: "os humilhados serão exaltados", e a gente confia nisso. Digo a muitas pessoas que têm, assim, uma discriminação com os ciganos, que têm ódio, que Deus disse que o ódio não cabe em canto nenhum. Ódio num presta não, o negócio é amar a teu próximo como a ti mesmo. Os errados que judiavam de Deus ele dizia: “pai, perdoa que eles são inocentes!” E nós pecadores não queremos perdoar uns aos outros, é erro nosso!. (L.C., 78 anos).

Nós somos peregrinos de Jesus... Nós fomos umas pessoas ambulantes e sofredoras, fomos uns verdadeiros peregrinos de Jesus. Jesus deixou pra nós ser o mensageiro, pra nós correr o mundo inteiro. De fato nós conhece muitos cantos: Maranhão, Bahia, Sergipe, Rio Grande do Norte. Nós caminhava, perambulava com animal, trocando, e daí por diante. (F, 75 anos).

Para os segmentos de maior idade, a origem do grupo está intimamente ligada a passagens da Bíblia sagrada. O próprio nomadismo é naturalizado como a gênese do grupo, período que remonta as suas origens, o que lhes dá certo ar de sagrado. É interessante notarmos a proximidade e a ligação entre os ciganos e personagens bíblicos como Abraão, Sara, Isaac, Moisés, Jesus, os Reis Magros etc. Estas narrativas expli- cam a própria concepção do nomadismo como sendo uma questão de destino, uma escolha ou concessão de Deus. Além disso, verificamos a imagem de Jesus como um nômade, um peregrino, imagem que também se faz presente em narrativas do catolicismo popular.

Para os informantes de uma faixa etária mais avançada, os ciganos são descendentes destas figuras bíblicas, "mensageiros" que andavam pelo mundo pregando a palavra de Deus, por isso perseguidos, mas seguidos por povos "peregrinos", como os ciganos.

Como nos aponta Weber (1982, p. 222), os ciganos vivem o presente explorando o passado, o que permite um senso de dignidade, "nutrido pela crença numa "missão" providencial e por uma crença numa honra específica perante Deus". Esta seria uma dignidade do "povo escolhido", alimentada pela crença de que os "últimos serão os primeiros".

Nestas narrativas, o passado fornece um status diferenciado, através dessa ideia de destino, que produz uma "estimativa positiva", que determina certa "honraria" ao povo cigano, visto aqui como um "povo escolhido". Assim, o fato de serem "mensageiros" ou "peregrinos", tal como fora Jesus, explica a própria constituição histórica do grupo. A peregrinação relaciona-se com o passado de nomadismo, a vida sofrida, a tradição. Já o fato de serem mensageiros de Deus explica a capacidade de vidência e os sentimentos de dignidade, que se relacionam com uma positivação do seu status social (Op. cit.).

As viagens ou andanças são pensadas pelos informantes como peregrinações ou viagens santas, que explicariam as primeiras migraçóes de ciganos pelo mundo. Nesta caminhada, os ciganos teriam chegado ao Egito. Como vimos na narrativa do Sr. L., se Jesus era pobre, iletrado, "alguém que andou muito pelos paises", ele também era um nômade, e os ciganos, enquanto seus seguidores, também possuem sua "ciência" e seu valor. A confiança em Deus justifica 
como pessoas que "nunca pegam numa enxada vive bem". Já o Sr. F. explica a divisão do mundo entre ciganos e "particulares" a partir de explicaçóes religiosas, o que por sua vez acaba explicando a divisão social entre nomadismo e sedentarização:

Vou lhe dizer consciente: o cigano de tradição era filho do Egito, então a tradição de cigano vem dos antigos. Agora, essa nação de cigano nosso, antes de tudo foi nosso Sr. Jesus Cristo que ficou no mundo. Os ciganos e os particular foram onde tá Jesus Cristo: - "Senhores, o que é que necessita"? Os ciganos disseram:

- "Senhor, necessita a viajar".

E Jesus disse: -"Senhor, dai liberdade aos seus caminho, pra vocês corrigir o mundo. Pode seguir os seus caminhos”. Agora a outra nação pediram pra morar. Agora que os ciganos são servos de Deus, e muita gente não reconhece isso. E daí nasceu essa origem dos ciganos (F. 75 anos).

Nestas narrativas encontramos explicaçôes bíblico-religiosas para a diversidade cultural: mundo dividido entre moradores (não ciganos) e andarilhos (ciganos). Os mais velhos mostraram-se excelentes narradores, descrevendo a saga de seus antepassados, construindo assim sua origem numa recuperação mítica do passado. A fé em Deus, que os tornou "mensageiros de Jesus", justifica a plasticidade e a vida nômade dos ciganos.

Note-se que nas falas dos mais idosos ocorre uma associação da fé com a etnicidade, pois falam de "fé", não de igrejas. Neste sentido a fé denota uma distinção entre "ter fé" e "viver a fé", ou seja, viver como Jesus viveu, viver como nômade, como peregrino:

Nós somos peregrinos de Jesus, por isso somos ciganos legítimos. Aqui ainda tem cigano da descendência do Egito, que sabe ler mão, fazer oração e daí por diante. Agora Deus vive entre os ciganos. Ele vê o nosso sonho, a nossa vida, o nosso sofrer (G, 75 anos).

Através do conhecimento da literatura bíblica, as narrativas buscam associá-la a experiências vividas pelos grupos. Por meio destes conhecimentos, os narradores encontram elementos que servem como referência por analogia. O passado, portanto, abarca diversos tempos, tais como o tempo em que Jesus andou pela terra e o tempo das perseguiçóes (longínquo), o tempo das andanças (dos ciganos de Sousa) e o tempo da parada (o momento atual), que se misturam para constituir uma história. Como nos aponta Bourdieu (1998, p. 183), falar de história é pressupor que a vida é uma história, inseparável dos acontecimentos de uma existência, concebida por meio de relatos dessa história.

As narrativas dos idosos sobre o "tempo de atrás" são marcadas por características que as tornam exemplares no universo estudado, pois representam um paradigma da história do grupo, nitidamente densas e míticas, numa tentativa de legitimar a origem e os antepassados do grupo. Nestas narrativas, os ciganos aparecem como um povo historicamente construído, cujas origens remetem a passagens bíblicas que, uma vez relacionadas, compóem o substrato simbólico da identidade atual.

Assim, tais narrativas funcionam como marcas do trabalho da memória coletiva, sumariando o passado grupal através de mitos de origem, ao mesmo tempo em que realizam reflexôes sobre as experiências históricas vividas. Sobretudo, tais narrativas preocupam-se em dar sentido ou lógica a certos eventos, relacionando passagens bíblicas com acontecimentos vividos e estabelecendo uma conexão entre eles.

As tradiçóes do grupo, à medida que são narradas pelos idosos, ligam-se a outras tradiçôes existentes no mundo externo, tradiçóes 
que, nesse sentido, aparecem como algo herdado, transmutado, adicionado, acionado nos processos de produçáo da história grupal.

\section{Consideraçóes finais}

O nomadismo, materializado nas representaçóes coletivas em torno do passado grupal, é o que permite às pessoas a identificação com uma história especifica. Como nos diz Bachelard (Op. cit., p. 39), a história é sempre construída por narrativas, que ao serem elaboradas adquirem continuidade ou duração.

A alusão a um tempo mítico, portanto, detém um valor positivo na forma de se conceberem como um grupo de pertencimento, pois o passado nômade contém qualidades simbólicas que amalgamam a ideia de cultura como um sistema simbólico (Eckert, 1993, p. 12).

É necessário frisar que embora as pessoas, independentemente de geração ou sexo, destaquem a importância do passado nômade, apenas as mais velhas referem-se à religiosidade como um elemento fundante da "ciganidade", bem como são as únicas que destacam a ligaçáo entre a origem do grupo e passagens bíblicas.

Os valores advindos deste tempo são mantidos por meio de recordaçóes, da memória, como fonte de sentimentos e afetividades e, mesmo já adaptados a novas circunstâncias, permanecendo um elemento extremamente significativo na medida em que servem como parâmetros de diferenciação entre ciganos e não ciganos, bem como um valor de positivação da sua identidade étnica.

Assim, há uma relação privilegiada entre memória e nomadismo que constitui as interpretaçóes sobre a origem dos grupos. Mas este trabalho de memória é tanto narrativo como construtivo. Deste modo, reelaboram-se o passado e as experiências por ele veiculadas, pois lembrar aparece como uma forma de durar, de estabelecer fronteiras culturais, sendo a religio- sidade um diferenciador para a população cigana com mais idade.

O passado nômade é requerido como elemento identitário, construído através da memória e das narrativas que exploram episódios bíblicos, recurso importantíssimo para a construção da coletividade cigana e do sistema de representaçóes sociais que permite uma visibilidade social, bem como o estabelecimento de suas especificidades culturais frente à sociedade não cigana.

Falar do passado é falar de um percurso trilhado, é falar de uma história vivida ou de uma história que se quer contar. E uma vida é, como diz Bourdieu (1980), inseparável do conjunto dos acontecimentos de uma existência individual ou coletiva.

\section{Nomads and Pilgrims: the Past as an Ele- ment of Identity among the Calon Gypsies in the City of Sousa-Paraíba}

abstract This work analyzes elements of gypsy identity found in their forms of collective identification, how this identity is narrated, and the elements that articulate a vision of social group. With this purpose, it chooses as its empirical model groups of gypsies residing in the city of Sousa (PB). It also analyzes the importance of religiosity for a significant portion of the gypsy community regarding its cultural identity.

keywords Gypsies. Identity. Memory. Religion. Narratives.

\section{Notas}

1. A cidade de Sousa localiza-se na mesorregião do sertão paraibano, regiáo nordeste do Brasil. Tem uma área de $842 \mathrm{~km}^{2}$, sendo o quinto maior território do estado. Localiza-se a $420 \mathrm{~km}$ da capital paraibana. A população do município, com base em dados do IBGE (2009), é de 65.930 habitantes. 
I72 Maria Patrícia Lopes Goldfarb

2. Cardoso de Oliveira (2000, p. 9) situa uma situação etnográfica como uma situação da pesquisa em que se desenvolvem padrốes de interação, mútuas percepçōes e expectativas que caracterizam o encontro entre pesquisadores e pesquisados. Assim, o etnógrafo recupera a si mesmo em sua etnografia, na medida em que se assume como um ator nesse encontro.

3. A pesquisa realizada entre a população cigana residente em Sousa no ano de 2004 desembocou na tese de doutorado intitulada $O$ Tempo de atrás: um estudo da construção da identidade cigana em Sousa-PB, defendida junto ao Programa de Pós-Graduação em Sociologia da UFPB.

4. Segundo Thompson, (1992, p. 44), a história oral é uma história construída em torno de pessoas. Ela lança a vida para dentro da própria história, e isso alarga seu campo de ação. Além disso, propicia o contato e a confiança entre pesquisadores e pesquisados.

5. Entre os ciganos de Sousa "juron" é uma denominação usada para definir os nâo ciganos, o que no dialeto cigano significa "animal", em oposição à "calon", que significa "homem".

6. Sant'Ana (1983, p. 21-22) nos fala que tanto estudiosos como os ciganos utilizaram a Bíblia para explicar sua origem e dispersão pelo mundo. Cita o exemplo dos ciganos Kalderash de Campinas, que recorrem à Bíblia para explicar suas origens, afirmando serem descendentes de uma das sete tribos de Israel, sendo, portanto, descendentes de Moisés. Além disso, acredita-se que os ciganos seriam descendentes do Egito, chegando à Europa Central e aí se apresentando como "peregrinos", egressos do Egito.

\section{Referências bibliográficas}

BACHELARD, Gaston. A Dialética da duraçâo. São Paulo: Ática, 1994.

BARTH, Frederic. Grupos étnicos e suas fronteiras. In: POUTGNAT, P; FENART-STREIFF, J. Teorias $d a$ Etnicidade. São Paulo: Difel, 1998.
BOSI, Ecléa. Memória e Sociedade. Lembranças de velhos. São Paulo: Companhia das Letras, 1994.

BOURDIEU, Pierre. Le Capital Social. Notes provisoires. In: Actes de La Recherche em Sciences Sociales, Paris, n. 31,1980 .

. A Ilusão Biográfica. In: AMADO, Janaina; FERREIRA, M. de M. Usos e Abusos da História Oral. Rio de Janeiro: Editora da Fundaçáo Getúlio Vargas, 1998.

CARDOSO DE OLIVEIRA, Roberto. O Trabalho do Antropólogo. São Paulo: UNESP, 2000.

ECKERT, Cornélia. Memória e Identidade. Ritmos e ressonâncias da duraçáo de uma comunidade de trabalho: mineiros do carvão (La Grand-Combe, França). In: Cadernos de Antropologia, no. 11, Porto Alegre: Editora da UFRGS, 1993.

GIUMBELLI, Emerson. Para além do "trabalho de campo": reflexóes supostamente malinowskianas. Rev. Brasileira de Ciências Sociais. vol.17, no. 48, 2002.

GOLDFARB, Maria Patrícia Lopes. O tempo de atrás: um estudo da construção da identidade cigana em Sousa-PB. Tese de doutorado. Programa de Pós-Graduação em Sociologia. Universidade Federal da Paraíba. João Pessoa, 2004.

HALBACHS, Maurice. A Memória coletiva. São Paulo: Vértice, Ed. Dos Tribunais, 1990.

SANT'ANA, Maria de Lourdes. Os ciganos: aspectos da organização social de um grupo cigano em Campinas. São Paulo: FFLCH/USP, 1983. (Antropologia, 4).

THIOLLENT, M.M (et alli). Crítica Metodológica, Investigação Social e Enquete Operária. São Paulo: Polis, 1982.

THOMPSON, P. A Voz do Passado. História Oral. Rio de Janeiro: Paz e Terra, 1992.

WEBER, Max. Ensaios de Sociologia. Rio de Janeiro: Guanabara Koogan, 1982.

Economia e sociedade: fundamentos da sociologia compreensiva. Brasília: Editora da UNB, 1994.

autora Maria Patrícia Lopes Goldfarb

Professora Adjunta de Antropologia / UFPB

Doutora em Sociologia / UFPB

Recebido em 07/03/2010

Aceito para publicação em 20/09/2010

cadernos de campo, São Paulo, n. 19, p. 165-172, 2010 